\title{
CHROMIUM REMOVAL USING TRICHODERMA VIRIDE AS BIOSORBENT
}

\author{
A.Niveditha ${ }^{1}$, Archna $^{2}$ \\ ${ }^{1}$ Department of Biotechnology, Sir M Visvesvaraya Institute of Technology, Bangalore-562157, India \\ ${ }^{2}$ Department of Chemical Engineering, M S Ramaiah Institute of Technology, Bangalore-560054, India
}

\begin{abstract}
Pollution of water by chromium is of serious concern, as it is widely used in textile industries, electroplating, leather tanning and metal finishing. Chromium exists in two oxidation states as trivalent [Cr (III)] and hexavalent [ $\mathrm{Cr}(\mathrm{VI})]$ of which $\mathrm{Cr}(\mathrm{VI})$ is more toxic. Many microorganisms have been used as biosorbents till date for biosorption of $\mathrm{Cr}$ (VI). This study involves the use of a fungal specie Trichoderma viride (NBAII-16) for the removal of hexavalent chromium. The effect of time, influence of pH, biomass dosage and initial metal ion concentration on the biosorption of $\mathrm{Cr}(\mathrm{VI})$ was investigated. For an initial concentration of $\mathrm{Cr}(\mathrm{VI})$ of 50ppm, the adsorption was found to be highest at a $\mathrm{pH}$ of 2, a contact time of 90mins and a sorbent dosage of $\operatorname{lgmDCM}$. The adsorption data were well fitted by Langmuir and Freundlich isotherms.
\end{abstract}

Keywords: Chromium[Cr(VI]), biosorption, isotherm, heavy metal

\section{INTRODUCTION}

Heavy metals which are toxic such as $\mathrm{Hg}, \mathrm{Cr}, \mathrm{Pb}, \mathrm{Zn}, \mathrm{Cu}$, $\mathrm{Ni}, \mathrm{Cd}, \mathrm{As}$, and $\mathrm{Co}$ and precious metals such as $\mathrm{Pt}, \mathrm{Ag}, \mathrm{Au}$, $\mathrm{Ru}$ and radio-nuclides like $\mathrm{U}, \mathrm{Th}, \mathrm{Ra}$ and $\mathrm{Rn}$ present at trace levels is of risk for human beings. Thus, effective removal of undesirable metals from wastes generated by textile industries, electroplating, etc., is an important and a highly challenging task (Zaied et.al., 2008) for environmental engineers. The polluted waters containing heavy metals enter and cause an adverse effect on the environment. The presence of these heavy metals varies from site to site and depends upon the source of specific pollutants. Heavy metal contamination of soil is a great environmental threat as it accumulates in soil and thus enter plant in large amounts and lastly the food chain (Stolt et.al, 2006).

Soils contaminated with heavy metal adversely affect the ecology, quality of agricultural products, agricultural productivity, water resources and hence seriously affect human beings and animals health (Resaee et.al, 2005).

The heavy metal contamination in soil not only changes composition of soil microbial community also adversely affects the soil characteristics (Giller et.al, 1998; Kozdrój et.al, 2001; Kurek et.al, 2004). This inturn affects the crop growth, as the metals interfere with metabolic functions in plants, including physiological and biochemical processes, inhibiting photosynthesis, respiration and degeneration of the cell organelles, sometimes leading to death of plants (Garbisu et.al., 2001; Schmidt 2003, Schwartz et.al., 2003).

Among the heavy metals, Chromium $(\mathrm{Cr})$ is one of the most important heavy metal which is extensively used in most of the industries. The present study includes removal of $\mathrm{Cr}(\mathrm{VI})$ from industrial effluent using biosorption with the fungal strain Trichoderma viride (NBAII-16).

\section{MATERIALS AND METHODS}

$\mathrm{Cr}$ (VI) biosorption was studied using an effluent taken from a leather tanning industry (name confidential) located in Peenya, Bangalore. The sample of effluent was analysed for concentration of $\mathrm{Cr}$ (VI). It was found that the concentration of $\mathrm{Cr}(\mathrm{VI})$ in the sample was $80-85 \mathrm{ppm}$.

\subsection{Fungal Strain}

The fungal strain of Trichoderma viride (NBAII-16) used for biosorption study was procured from Gandhi Krishi Vignana Kendra (GKVK), Bangalore. The fungal strain was subcultured in potato dextrose agar (PDA) slant (39.9 g/l) comprising streptomycin $0.003 \mathrm{~g} / \mathrm{l}$ for antibacterial activity.

The Trichoderma viride(NBAII-16) was cultivated on broth liquid medium at a temperature of $25^{\circ} \mathrm{C}$ using a rotary incubator shaker at $120 \mathrm{rpm}$. The broth liquid media was composed of (g/l)-bactodextrose 20; bactopepton $10 ; \mathrm{NaCl}$ $0.2 ; \mathrm{KCl} 0.1 ; \mathrm{CaCl}_{2} .2 \mathrm{H}_{2} \mathrm{O} 0.1 ; \mathrm{K}_{2} \mathrm{HPO}_{4} 0.5 ; \mathrm{NaHCO}_{3} 0.05$; $\mathrm{MgSO}_{4} 0.25 ; \mathrm{FeSO}_{4} .7 \mathrm{H}_{2} \mathrm{O} 0.005$ at a $\mathrm{pH}$ of 5 . The biomass was harvested by filtering through muslin cloth. The harvested biomass was washed and dried for use in biosorption studies for the removal of $\mathrm{Cr}$ (VI). (Niveditha et.al, 2013)

\subsection{Batch Studies for the Biosorption of Chromium} (VI)

Batch studies for the sorption of $\mathrm{Cr}$ (VI) were conducted to study the effect of biomass dosage, contact time, $\mathrm{pH}$ and initial metal ion concentration. The biosorption experiments were conducted in Erlenmeyer flask of $250 \mathrm{ml}$ on shaking incubator at a speed of $120 \mathrm{rpm}$ at $25^{\circ} \mathrm{C}$. The biomass was varied from 0.5 to $3.0 \mathrm{~g}$ for the study. The contact time was varied from 30 to 180 minutes for optimization. The $\mathrm{pH}$ 
range of 2 to 7 was used for the experiment. The effluent was diluted to prepare $10 \mathrm{ppm}, 25 \mathrm{ppm}$ and $50 \mathrm{ppm}$ solutions of $\mathrm{Cr}(\mathrm{VI})$. The analysis of $\mathrm{Cr}(\mathrm{VI})$ was done using Atomic Absorption Spectrophotometer (GBC-932).

\section{RESULTS AND DISCUSSION}

The biosorption of Chromium (VI) using live fungal strain, Trichoderma viride(NBAII-16) was evaluated under variable conditions for different initial chromium concentration.

\subsection{Effect of Biomass Dosage}

In batch experiment, it was observed that the percentage adsorption increased with increase in live biomass (Figure1). The result suggests that increase in biomass increases adsorption area, thus enhancing metal ion uptake. Maximum biosorption was observed as $41.88 \%$ using $3 \mathrm{~g}$ of biomass. The results agree with other biosorbent studies in literature (Narsi et.al, 2007; Niveditha et.al, 2013).

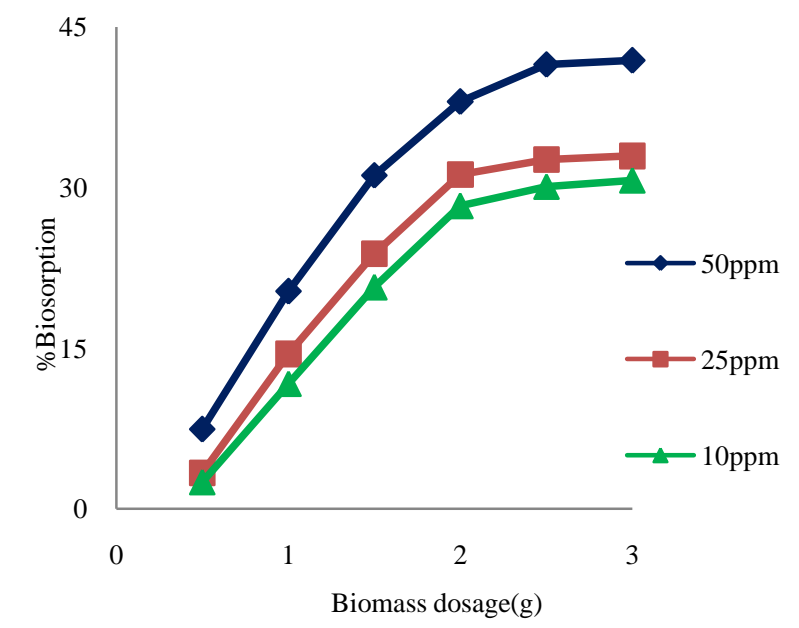

Fig 1: Variation of removal of Cr (VI) with varying live biomass dosage.

\subsection{Effect of Contact Time}

In batch experiment, it was observed that the percentage adsorption increased with increase in time (Figure2). The results show that maximum chromium removal by live fungal strain was at first $90 \mathrm{~min}$ of study. After that no appreciable amount of chromium removal was found. The rapid sorption period indicates surface adsorption. It is seen that there is a sudden increase in rate of adsorption initially which reaches equilibrium with increase in time. This result agrees with $\mathrm{Cr}$ (VI) removal done using various other biomasses (Narsi et.al, 2007; Niveditha et.al, 2013).

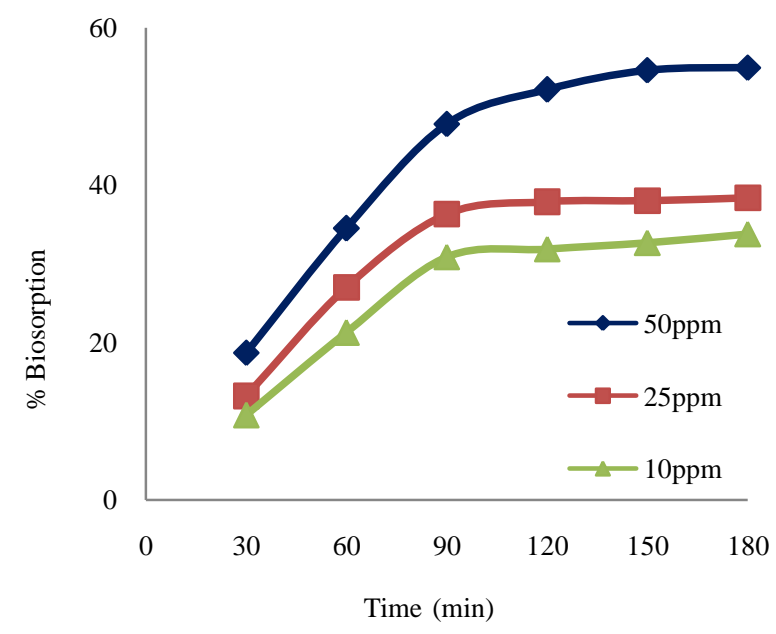

Fig 2: Variation of removal of Cr (VI) with varying contact time using live biomass.

\subsection{Effect of pH}

In batch experiment, it was observed that the percentage adsorption decreased with increase in $\mathrm{pH}$. Maximum biosorption was observed as $54.48 \%$ at $\mathrm{pH}$ of 2 and minimum of $24.04 \%$ at $\mathrm{pH}$ of 7 (Figure3) for 50ppm chromium solution using live biomass. The results agree with the biosorbent studies in the literature (Narshi et.al, 2007; Niveditha et.al, 2013).

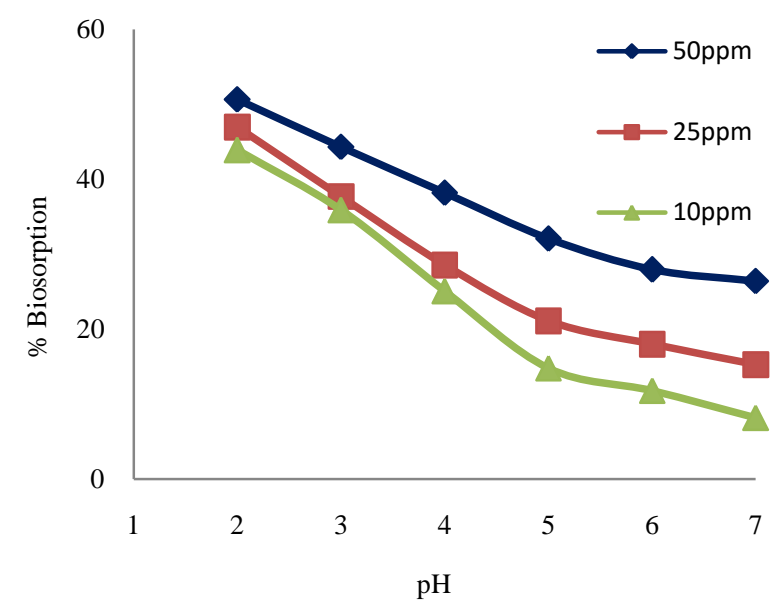

Fig 3: Variation of removal of $\mathrm{Cr}$ (VI) with varying $\mathrm{pH}$ using live biomass.

\subsection{Effect of Initial Chromium (VI) Concentration}

The batch study for the effect of initial Chromium (VI) concentration in effluent shows that percentage biosorption increased as the concentration changed from $10 \mathrm{mg} / \mathrm{l}$ to 50 $\mathrm{mg} / \mathrm{l}$ (Figure4). The reason could be that at higher initial metal concentration, more metal ions were available for interaction with the binding sites. Maximum adsorption was $20.32 \%$ by the live biomass for $50 \mathrm{mg} / \mathrm{l}$ of initial chromium concentration. This result agrees with the work of Narsi et.al, 2007. 


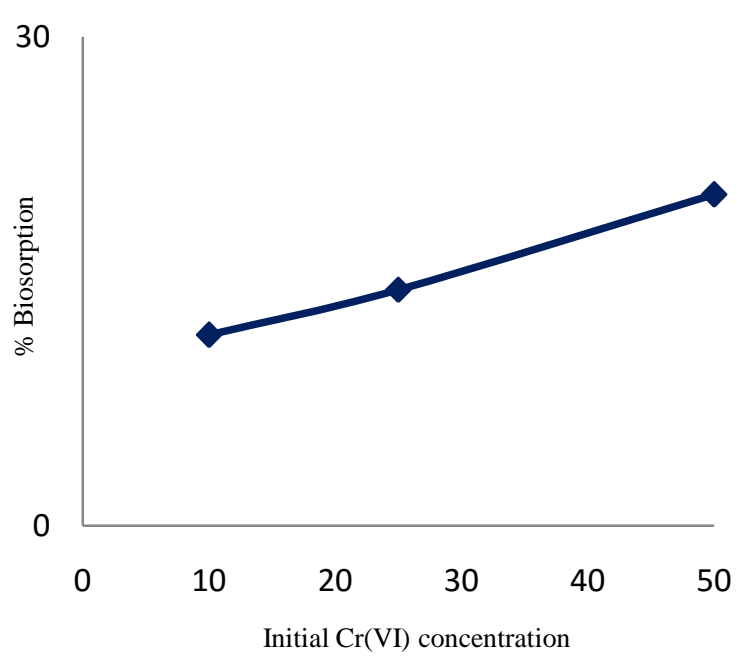

Fig 4: Variation of removal of $\mathrm{Cr}$ (VI) with varying initial $\mathrm{Cr}(\mathrm{VI})$ concentration for $1 \mathrm{~g}$ of biomass.

\subsection{Langmuir Isotherm}

The batch isothermal study was done for biosorption of $\mathrm{Cr}$ (VI) by the fungal strain. $\mathrm{Cr}$ (Vl) adsorption followed Langmuir isotherm (Figure5). The Langmuir model assumed that the sorption of metal ion occurs on homogenous surface by monolayer adsorption with no interaction between adsorbate ions.

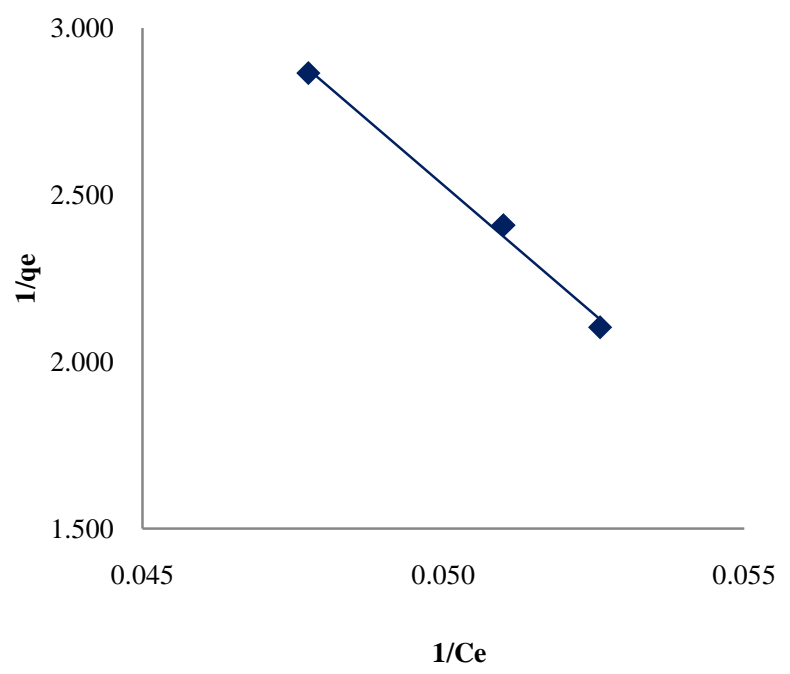

Fig 5: Langmuir Isotherm for biosorption of $\mathrm{Cr}$ (VI) for an initial concentration of $50 \mathrm{ppm}$.

\subsection{Freundlich Isotherm}

The batch study conducted at isothermal conditions was done for biosorption of $\mathrm{Cr}$ (VI) by fungal strain. $\mathrm{Cr}(\mathrm{Vl})$ sorption followed Freundlich isotherm (Figure 6). The Freundlich model assumed that the sorption of metal ion occurs on homogenous surface by monolayer adsorption with no interaction between adsorbate ions.

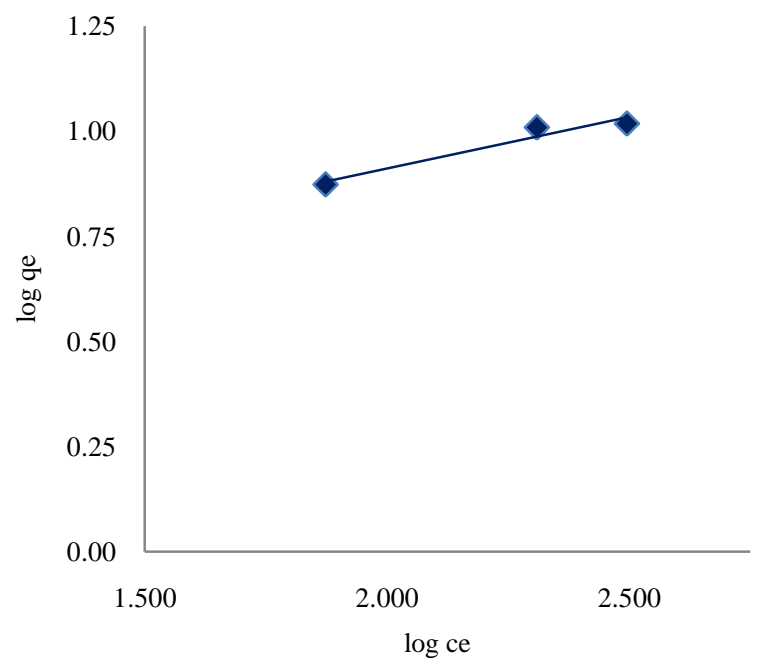

Fig 6: Freundlich Isotherm for biosorption of $\mathrm{Cr}$ (VI) for an initial concentration of $50 \mathrm{ppm}$.

\section{CONCLUSION}

We can conclude that live Trichoderma viride(NBAII-16) has the potential to remove heavy metals. This is confirmed from the batch study conducted which shows chromium(VI) removal from industrial effluents. The results of Freundlich and Langmuir isotherm show clearly that the fungi is a good biosorbent. Freundlich and Langmuir constants obtained were very less thus showing that the fungal strain works better at low concentrations of chromium. Future studies can be carried out for removal of other heavy metals.

\section{REFERENCES}

[1]. Zaied.K.A, A.Mageed, E.A.Fayzalla, A.E.Sharief and A.A.Zehry, "Enhancement biosorption of heavy metals from factory effluents via recombinants induced in yeast and bacteria," Journal of Basic Applied Science, vol. 2, pp. 701 717, 2008.

[2]. Stolt.P, Asp.H and Hultin.S, "Genetic variation in wheat cadmium accumulation on soils with different cadmium concentrations," Journal of. Agron. Crop Science, vol. 192, pp. 201-208, 2006.

[3]. Resaee.J, Derayat.S.B, Mortazavi.Y and Jafarzadeh.M.T, "Removal of Mercury from chlor-alkali industry wastewater using Acetobacterxylinumcellulose," American Journal of Environmental Sciences, vol. 1(2), pp: 102-105, 2005.

[4]. Garbisu.C and Alkorta.I, "Phytoextraction: A cost effective plant-based technology for the removal of metals from the environment," Biores Technol. vol. 77(3), pp. 229236, 2001.

[5]. Schmidt.U, "The effect of chemical soil manipulation on mobility, plant accumulation, and leaching of heavy metals," Journal of Environmental Qual., vol. 32, pp. 1939-1954, 2003.

[6]. Schwartz.C, Echevarria.G, and Morel.J.L, "Phytoextraction of cadmium with Thlaspicaerulescens," Plant Soil, vol. 249(1), pp. 27-35, 2003. 
[7]. Giller.K.E, Witter.E and McGrath.S.P, "Toxicity of heavy metals to microorganism and microbial processes in agricultural soils", A review, Soil Biology and Biochemistry, vol. 30 (10-11), pp. 1389-1414, 1998.

[8]. Kozdrój.J and Amdvan Elsas.J.D, "Structural diversity of microbial communities in arable soils of a heavily industrialized area determined by PCR-DGGE finger printing and FAME profiling," Applied Soil Ecology, vol. 17 (1), pp. 31-42, 2001.

[9]. Kurek.E and Bollag.J.M, "Microbial immobilization of cadmium released from $\mathrm{CdO}$ in the soil," Biogeochemistry, vol. 69(2), pp. 227-239, 2004.

[10]. Narsi.R.Bishnoi, Rajendar Kumar and Kiran Bishnoi, "Biosorption of $\mathrm{Cr}$ (VI) with Trichoderma viride immobilized fungal biomass and cell free Ca-alginate beads," Indian Journal of Experimental Biology, vol. 45, pp. 657-664, 2007.

[11]. A. Niveditha and Archna, "Biosorption of Chromium (VI) using Trichoderma viride," International Conference on "Convergence of Science, Engineering \& Management" A Global Perspective - II Edition, pp. 209, 2013. 